\title{
An Investigation of the Effect of Parameters and Chip Slenderness Ratio on Drilling Process Quality of AISI 1050 Steel
}

\author{
Zülküf Demir and Rifat Yakut \\ Mechanical and Manufacturing Engineering of Technology, Faculty of Batman University, 72100 Batman, Turkey \\ Correspondence should be addressed to Rifat Yakut; rifat45@gmail.com
}

Received 6 January 2018; Revised 30 March 2018; Accepted 5 April 2018; Published 8 May 2018

Academic Editor: Wei Zhou

Copyright (C) 2018 Zülküf Demir and Rifat Yakut. This is an open access article distributed under the Creative Commons Attribution License, which permits unrestricted use, distribution, and reproduction in any medium, provided the original work is properly cited.

The chip slenderness ratio is a vital parameter in theoretical and applicable machining operations. In predrilled drilling operations of AISI 1050 steel alloy, HSS drills were employed, and the effect of the selected parameters on the chip slenderness ratio and also the effect of the chip slenderness ratio on the thrust force, surface roughness, drilled hole delamination, tool wear, and chip morphology were investigated. The major parameters, influential on the chip slenderness ratio, were feed rate and point angle, while spindle speed was too small to be negligible. With increasing the chip slenderness ratio, the thrust force and the tool wear decreased, which resulted in appropriate chip morphology, but there were increases in surface roughness. However, the chip slenderness ratio had no effect on the drilled hole delamination.

\section{Introduction}

Drilling process is a metal cutting method, which processes metal pieces in required geometry and dimension, in manufacturing area [1]. This manufacturing method has an important place as it is used about $33 \%$ among traditional manufacturing methods [2]. In the drilling process, researchers conducted many works after having completed complicated operations and manufacturing processes in order to obtain the required highest sensibility and best quality [3]. A lot of parameters such as drill point angle, material used for drilling, and properties of drilling equipment affect the drilling process. The tool equipment affects the demented of the drilled hole, the tool wear, the surface quality, and the chip length and thus the chip morphology [4]. As the feed rate increases, the surface quality is influenced inversely, and in other words, the surface roughness increases. Because the thrust force and the tool wear decrease at high spindle speeds and drill point angles, the surface roughness values decrease; thus, the surface quality improves. However, the process temperature and drilled hole delamination increase at high spindle speeds and drill point angles [5]. The delamination size of the drilled hole depends on the thrust force and feed rate in drilling processes [6,7]. Besides, thrust force increases the drilled hole delamination and the tool wear [8]. While the numbers of the drilled hole increase, the tool wear ratio increases as well [9]. As the chip height and thrust force increase due to increase in the feed rate, the chip height and the thrust force decrease with increase in spindle speed $[10,11]$.

Furthermore, the feed rate is a significant parameter, affecting the process quality and the surface roughness, more than the spindle speed in the drilling process [12-20]. With sufficient increase in the thrust force in the drilling process, the web thickness of the drill and the relief angle increase; otherwise, the drill point angle and the helical angle decrease $[21,22]$. However, with increase in the feed rate and point angle, the thrust force and surface roughness increase [23]. In the drilling process, vibration, tool wear, and dry process conditions cause changes in the diameter of the drilled hole [24]. At low cutting speeds and feed rates, due to the requested chip morphology availability, a better performance is obtainable in drilling processes. In addition, the tool point angle does not significantly affect the process temperature [25]. During the process, discontinuous and short shaped chips are obtained, due to the intermittent plastic deformation at low spindle speeds. With increasing the drill point angle and the spindle speed, the thrust force, resulting from the applied pressure on workpiece material by the drill point, decreases. Chip thickness varies considerably on all along the cutting edge during a cycle of the drill point 


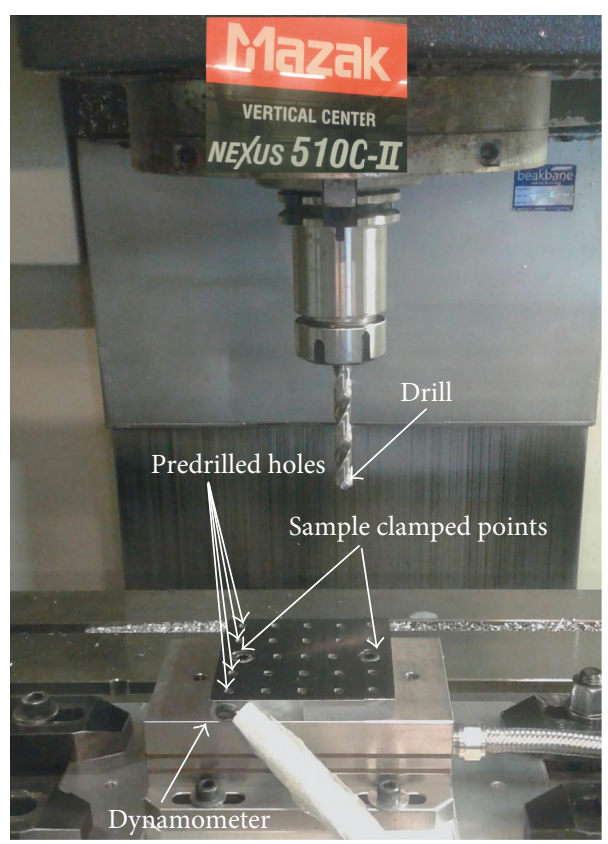

(a)

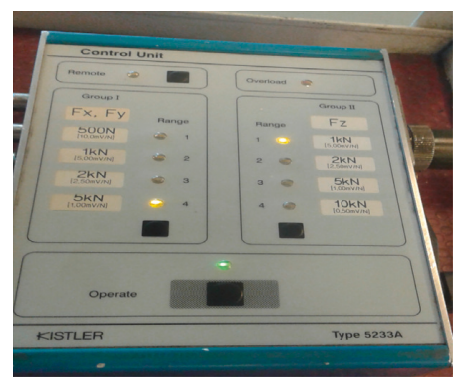

(b)

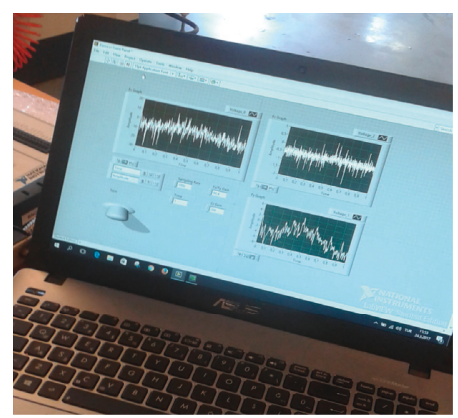

(c)

Figure 1: Experimental setup: (a) CNC milling machine, (b) 5233A-type dynamometer, and (c) computer.

[26]. With increasing the cutting conditions, the morphology of chip structure changes into a brittle shape from ductile. With enhancing the feed rate, the chip height increases, and also the thrust force, the drilled hole delamination, the surface roughness, and the tool wear increase as well [11]. Conical cutting edge, starting from the drill point, causes changes in cutting force all along the cutting edge of the drill [27]. Because the conical geometry is formed by the point angle of drill, the main feature of the drilling process shows differences from all along the cutting edge. While the feed rate gets the maximum ratio at the outmost diameter of the drill, it approaches to zero value toward the point axis of the drill where it constitutes core of the drill because of decrease in the diameter [28].

The chip slenderness ratio is the proportion of cutting depth to feed rate, which is the vital parameter to affect the outcomes, in machining. Therefore, the investigation of the chip slenderness ratio is the main phenomenon. Furthermore, the goal of this study is to investigate the effect of the chip slenderness ratio on the predrilled drilling process. In the literature, it is identified as a ratio of the depth of cutting to the feed rate, constituting an important parameter in machining operations. In drilling processes, due to the fact that the depth of the chip depends on the diameter of the drilled hole and the drill point, the chip slenderness ratio was calculated by the ratio of the square of the feed rate to the tool chip contact area. Considering the geometry of the drill point, the chip area was calculated mathematically depending on the drill point angle. The chip areas were calculated by crossing these two measured geometric dimensions. The effects of the drill point angle, spindle speed, and feed rate on the chip slenderness ratio were investigated during the study. In addition, with the
TABLE 1: Mechanical characteristics and chemical components of AISI 1050 alloy steel.

\begin{tabular}{lc}
\hline Mechanical characteristics & \\
Intensity & $7.85 \mathrm{~g} / \mathrm{cm}^{3}$ \\
Stress strength & $690 \mathrm{MPa}$ \\
Tensile strength & $580 \mathrm{MPa}$ \\
Slip modulus & $80 \mathrm{GPa}$ \\
Elastic modulus & $190-210 \mathrm{GPa}$ \\
Poisson's ratio & $0.27-0.30$ \\
Brinell hardness value & 197 \\
Heat conductivity & $49.8 \mathrm{~W} / \mathrm{mK}$ \\
\hline Chemical components & \\
Name of the & Percentage \\
element in & $(\%) \mathrm{ratio}$ of \\
composition & composition \\
$\mathrm{C}$ & $0.47-0.55$ \\
Mn & $0.6-0.90$ \\
$\mathrm{P}$ & $\leq 0.040$ \\
$\mathrm{~S}$ & $\leq 0.050$ \\
Fe & $98.46-98.92$ \\
\hline
\end{tabular}

help of the calculated chip area from this study, theoretical chip slenderness ratios were calculated.

\section{Experimental Procedure}

The experiments were conducted on Mazak Vertical Center CNC Milling Machine, which is the NEXUS 510 C-II model as shown in Figure 1. AISI 1050 alloy steel samples were prepared as $100 \times 100 \times 15 \mathrm{~mm}^{3}$ dimensions. The samples were predrilled $5 \mathrm{~mm}$ in diameter before the experiment. The distance was arranged as $20 \mathrm{~mm}$ between the centers of 


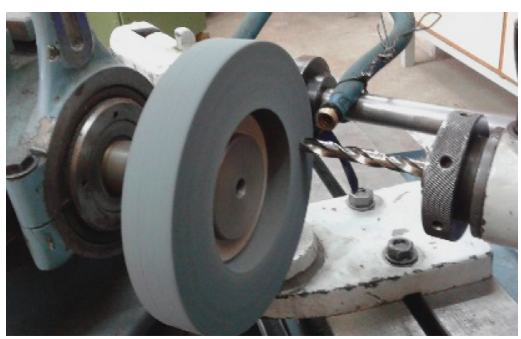

(a)

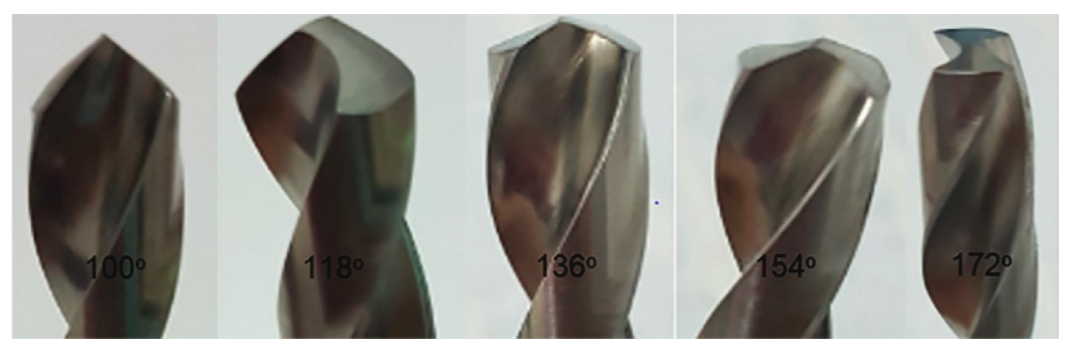

(b)

Figure 2: (a) Tool grinding machine and (b) drills with different point angles.

TABle 2: Characteristics of HSS drill points.

\begin{tabular}{lc}
\hline Drill diameter $(\mathrm{mm})$ & $10 \pm 0.01$ \\
Type of drill & 2-Helical channel, HSS \\
Drill point angle $\left(^{\circ}\right)$ & $100,118,136,154$ \\
Helical angle $\left(^{\circ}\right)$ & 30 \\
Handle length $(\mathrm{mm})$ & 46 \\
Type of handle & Cylindrical \\
Total length $(\mathrm{mm})$ & 133 \\
\hline
\end{tabular}

the drilled holes on the samples. The chemical components and mechanical characteristics of the AISI 1050 alloy steel are shown in Table 1. During the drilling process, the thrust force was measured with Kistler 5233A Dynamometer which is in Newton unit.

With the help of the depth micrometer, the drilled hole delamination was measured as $\mu \mathrm{m}$ unit at 4 different points, which is $5 \mathrm{~mm}$ in depth, and the arithmetic average of these values was taken into account. Wear areas of the drill points were monitored with Stereo LEICA Z16 APO microscope, and images were recorded. Surface roughness values were measured as $0.8 \mathrm{~mm}$ by using TR 200 TIME SIRF, a surface roughness value device.

During the experimental study, 4 different drill point angle values were selected: $100^{\circ}, 118^{\circ}, 136^{\circ}$, and $154^{\circ}$. The drill points were grinded at selected point angles by using the tool grinding machine, as shown in Figure 2(a). Pictures of the grinded drill points can also be seen in Figure 2(b). The geometrical properties of HSS drill points are shown in Table 2.

\section{Theory of Cutting Edge Geometry}

3.1. Geometry of Chip Analyses. The length of the cutting edge is formed depending on the angle of the drill point during the drilling process. Therefore, the geometry of drill is vital for drilling processes because of changing the cutting speed and showing differences throughout the cutting edge. Cutting speed gets the maximum ratio at the outmost diameter of the drill, and it decreases and approaches to zero toward the axis of the drill where the drill constitutes core [28]. The angle of the drill point has an important influence on the length of the cutting edge in the drilling process.

The geometry of the drill point is shown in Figure 3. In this figure, $\varnothing d_{\mathrm{o}}$ is the diameter of the predrilled hole of the

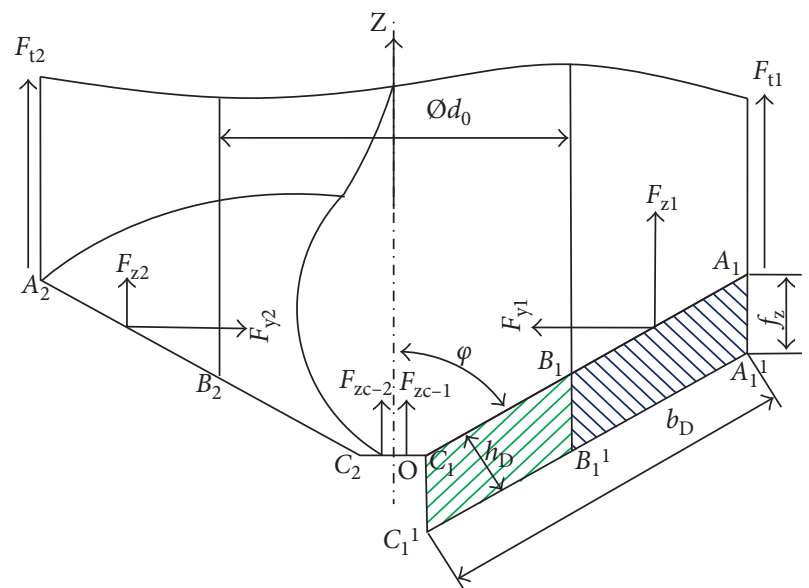

FIGURE 3: Geometry of the drill point [29].

workpiece sample before experimental processes. Effective forces on 1st and 2nd cutting edges of the drill were shown, respectively, as $F_{\mathrm{t} 1}$ and $F_{\mathrm{t} 2}$ tangential forces, $F_{\mathrm{z} 1}$ and $F_{\mathrm{z} 2}$ thrust forces, and $F_{\mathrm{y} 1}$ and $F_{\mathrm{y} 2}$ radial forces in the revolving direction. $F_{\mathrm{zc}-1}$ and $F_{\mathrm{zc}-2}$ are the effective thrust forces on the core of the drill point. $\Phi / 2=\varphi$ is half of the value of the drill point angle. Besides, the values of the point angles used in this study are $\Phi_{1}, \Phi_{2}, \Phi_{3}$, and $\Phi_{4}$, respectively, and they are equal to $100^{\circ}, 118^{\circ}, 136^{\circ}$, and $154^{\circ}$, respectively.

In this experimental study, in order to eliminate the effects of the drill core, holes were predrilled $5 \mathrm{~mm}$ in diameter. The dimensions of the cutting edges of the drills, used in experimental, drilling processes, in which the surplus were not predrilled, are calculable as seen in (1), depending on the geometry of the tip of the drill, as shown in Figure 4 according to predrilling diameters and drill point angle:

$$
l=\left|C_{1} A_{1}\right|=b_{\mathrm{D}}=\frac{d_{\mathrm{h}}-d_{\mathrm{o}}}{2 \cdot \sin \varphi} \mathrm{mm} .
$$

The uncut chip height $\left(h_{\mathrm{D}}\right)$ can be calculated based on the feed rate $\left(f_{\mathrm{z}}\right)$ and point angle $(\varphi)$ by using (2), in accordance with the geometry of the drill point, as shown in Figure 4. Since the height of the chip does not change depending on the predrilling diameter, the following equation is valid for both predrilled and without predrilled drilling processes: 


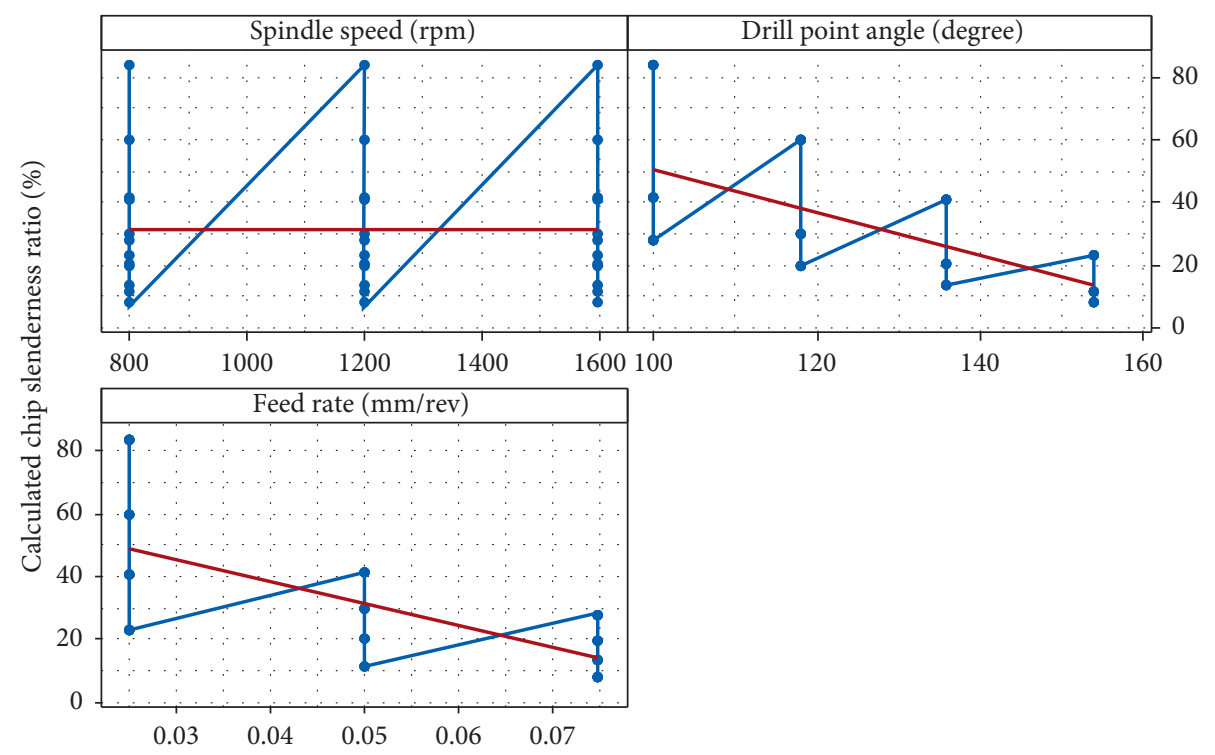

FIGURE 4: Effects of the selected parameters on the calculated chip slenderness ratios.

$$
h_{\mathrm{D}}=h_{\mathrm{De}}=f_{\mathrm{z}} \cdot \cos \varphi \mathrm{mm}
$$

In this experimental study, as surplus were predrilled $5 \mathrm{~mm}$ in diameter, the influential chip width and height values were demonstrated with $b_{\text {De }}$ and $h_{\text {De }}$, respectively.

$$
l_{\mathrm{e}}=\left|C_{1} A_{1}\right|=b_{\mathrm{De}}=\frac{d_{\mathrm{h}}-d_{\mathrm{o}}}{2 \cdot \sin \varphi} \mathrm{mm} \text {. }
$$

In these circumstances, the effective chip area $\left(A_{\mathrm{e}}\right)$ and chip width $\left(b_{\mathrm{De}}\right)$, depending on the chip height $\left(h_{\mathrm{De}}\right)$, can be calculated in accordance with the following equation:

$$
A_{\mathrm{ce}}=A_{\mathrm{ce}}\left|B_{1} B_{1}^{1}-A_{1} A_{1}^{1}\right|=h_{\mathrm{De}} \cdot b_{\mathrm{De}} \mathrm{mm}^{2} \text {. }
$$

In this experimental study, 4 different drill point angles were selected. These were represented with $\Phi_{1}, \Phi_{2}, \Phi_{3}$, and $\Phi_{4}$ symbols, and they were selected as $100^{\circ}, 118^{\circ}, 136^{\circ}$, and $154^{\circ}$, respectively.

According to the geometry of the drill point, the length of the cutting edge without predrilled hole $(l)$, and the length of cutting edge with predrilled hole $\left(l_{\mathrm{e}}\right)$, in other words, the uncut chip width values $\left(b_{\mathrm{D}}\right)$ and $\left(b_{\mathrm{De}}\right)$, showed differences depending on the change in the drill point angle.

In calculating the chip slenderness ratio, the chip width $\left(b_{\text {De }}\right)$, the chip height $\left(h_{\text {De }}\right)$, and the chip area $\left(A_{\text {ce }}\right)$ values were taken into consideration in predrilled drilling operations, depending on the drill point angles by using (1)-(4).

3.2. Analysis of the Chip Slenderness Ratio. The chip slenderness ratio is an important parameter when the feed rate of cutting depth in expanded cutting speed law is considered. This ratio is named as "chip slenderness factor" or "chip morphology." For the same chip contact area, the chip slenderness ratio is high at higher selected chip cutting depths, whereas it is low at smaller selected chip cutting depths. Manufacturers investigate the effect of the cutting depth and feed rate on the chip slenderness ratio simultaneously in real applicable machining operations. The optimum chip slenderness ratio is 5:1 according to the results in the literature.

However, this value $(5: 1)$ is not valid for the turning operations because the selected feed rates are bigger than the selected cutting depths. Measuring of the chip dimensions, obtained from the experiments, such as chip thickness and chip width, is too difficult. Therefore, the calculated chip slenderness ratio derived from (5)-(7) was taken into consideration. The chip contact area can be written as demonstrated in the following equations in machining operations:

$$
A=a \cdot f .
$$

As seen in the following equation, the chip slenderness ratio $(G)$ can be identified as the rate of the depth of cutting (a) to the feed rate $(f)$ :

$$
G=\frac{a}{f}
$$

When the common solution of (5) and (6) is considered, the chip slenderness ratio $(G)$ can be calculated by the ratio of the chip contact area $(A)$ to the square of the feed rate $\left(f^{2}\right)$ :

$$
G=\frac{A}{f^{2}}
$$

\section{Results and Discussion}

4.1. Effects of the Selected Parameters on the Chip Slenderness Ratio. The chip slenderness ratio is an operational parameter accepted by researchers, working in machining manufacturing area. This parameter is demonstrated as the ratio of selected chip depth $(a)$ to the feed rate $(f)$ [30]. Feed rate is an important result in machining manufacturing operation, and it is the most important parameter determining the quality of the operation. Due to the fact that 
the chip slenderness ratio is expressed as the ratio of the chip depth to the feed rate (6), the effect of this ratio for operation is important. As the chip depth can be selected by the operator in milling and turning operations, this ratio can be directly considered as the ratio of the chip depth to the feed rate. However, in drilling processes, the chip depth is based directly on the diameter of hole to be drilled; in short, it is based on the diameter of the selected drill. So, this ratio should be considered as the ratio of the chip area to the feed rate square (7), and it should also be considered for conducting investigations and analysis in this study.

In this study, chip areas were investigated as calculated (theoretical) chip areas. The calculated (theoretical) chip areas were calculated using (2)-(4) and depending on the geometry of the drill point as shown in Figure 3.

It was investigated that the effects of parameters should be calculated by chip slenderness ratios in Figure 4. The calculated chip slenderness ratio was between 7.72 and 84.00. Differences between theoretical chip slenderness ratios were numerically high, but it was determined that chip slenderness ratios are directly proportional to the change in accordance with the selected parameters. The most effective parameters on the chip slenderness ratio were feed rate and angle of the drill point. When both feed rate and point angle increase, the chip slenderness ratio decreases linearly as shown in Figure 4. However, the effect of spindle speed on the chip slenderness ratio is too little.

Effects of the spindle speed on the theoretical chip slenderness ratio should be zero according to (6) and (7).

In the circumstance, it is concluded that geometrical and mathematical equations providing the trust results, theoretically, depend on the selected parameters. The highest value of the theoretical chip slenderness ratio was 84 and the lowest 7.72 .

4.2. Effects of the Chip Slenderness Ratio on Thrust Force. During drilling operations, thrust force is one of the important factors determining the quality of process and supplying information about the results. If the thrust force is low during the operation, this means that operation quality is high. In Figure 5, it is seen that the thrust force decreased when the chip slenderness ratio increased. On the other hand, it was also seen that the chip slenderness ratio decreased collaterally with the thrust force when the drill point angle increased for the theoretical chip slenderness ratio.

However, with increase in the theoretical chip slenderness ratio, decrease in thrust force was observed.

As demonstrated in Figure 5, the lowest thrust force values were obtained as 274.70 and $292.09 \mathrm{~N}$ at the theoretical chip slenderness ratio of 84 . However, the spindle speed had no effects on the theoretical chip slenderness ratio depending on the geometry of the drill point. On the contrary, the change resulted in only depending on the feed rate and the drill point angle.

4.3. Effects of the Chip Slenderness Ratio on Surface Roughness. Because of the chip slenderness ratio directly depends on the feed rate, the most effective parameter on surface roughness,

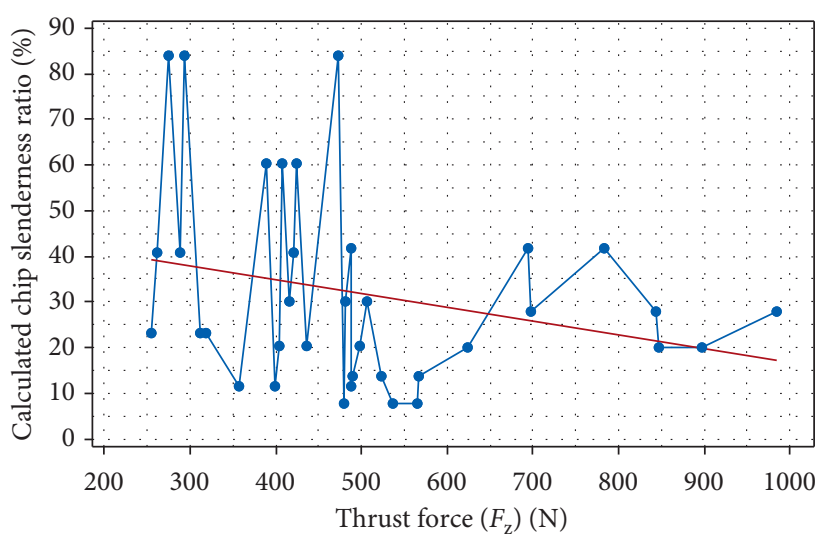

FIGURE 5: Effects of the experimental and theoretical chip slenderness ratios on the thrust force.

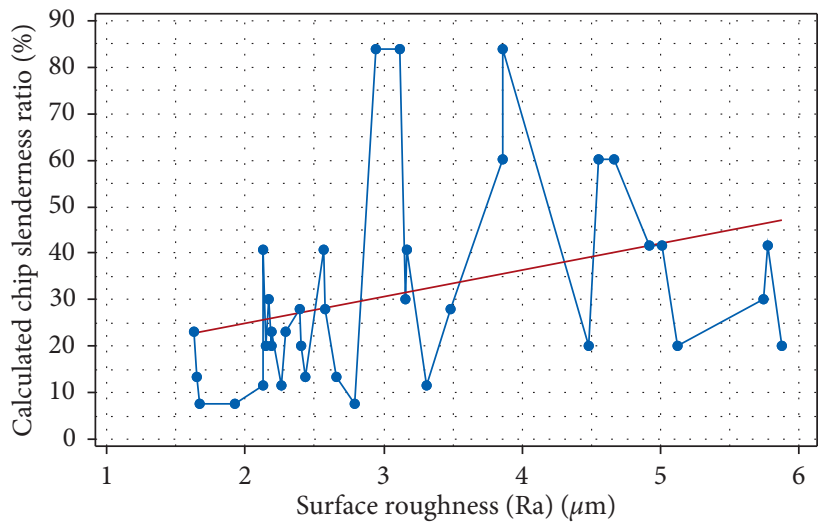

FIgURE 6: The effect of the calculated chip slenderness ratios on the surface roughness.

thus on the chip slenderness ratio is the most influential parameter on surface roughness. According to the graph in Figure 6, when the chip slenderness ratio increased, the values of surface roughness also increased, but surface quality decreased.

At the highest (60-80) and the lowest (7-20) chip slenderness ratio values, the maximum and the minimum surface roughness values were $4.50 \mu \mathrm{m}$ and $1.6 \mu \mathrm{m}$, respectively, as shown in Figure 6.

\subsection{Effect of the Chip Slenderness Ratio on Drilled Hole} Delamination. Due to the fact that the drilled hole delamination in drilling operations mostly depends on the motions of the tool and the interactions between the tool and the workpiece, it is not much affected by the chip slenderness ratio. The effect of the theoretical chip slenderness ratio on the delamination of the drilled hole is demonstrated in Figure 7. According to the results, the effect of the chip slenderness ratio on the delamination was unclear, and change in delamination values was determined depending on the changes in the chip slenderness ratio. Hole delamination cannot be investigated depending on the chip slenderness factor. 


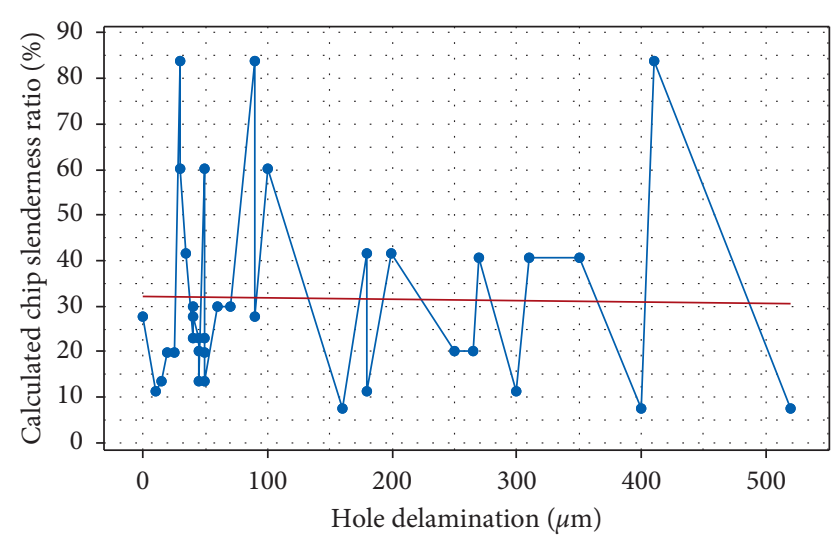

Figure 7: Effect of the calculated chip slenderness ratios on the drilled hole delamination.

\subsection{The Effect of the Calculated Chip Slenderness Ratio on Chip} Morphology. In drilling operations, morphology is the most important marker, affecting the operation quality. In this study, the effect of the chip slenderness ratio on the chip morphology was demonstrated, as shown in Figures 8(a)8 (c), for selecting $0.025,0.050$, and $0.075 \mathrm{~mm} / \mathrm{rev}$ feed rates, respectively.

As shown in Figure $8(\mathrm{a})$, at $0.025 \mathrm{~mm} / \mathrm{rev}$ feed rate, with increasing the drill point angle, the chip morphology changed from brittle and short forms to continuous. Furthermore, at lower point angles, especially at $100^{\circ}$ and $118^{\circ}$, the serrating chip form resulted in the obtained chips, while the serrating chip formation decreased at higher point angles, as $136^{\circ}$ and $154^{\circ}$. The serrated chip formation demonstrates the quantity of the vibrations, undesired phenomenon during the machining operations because of causing the severe wear and shorter tool life. However, at $0.05 \mathrm{~mm} / \mathrm{rev}$ feed rate, as shown in Figure 8(b), at higher point angles, especially at $136^{\circ}$ and $154^{\circ}$, and at collateral spindle speed, $1600 \mathrm{rpm}$ spindle speed, the serrated chip formation decreased. At $0.075 \mathrm{~mm} / \mathrm{rev}$ feed rate, as shown in Figure 8 (c), at lower point angles, $100^{\circ}$ and $118^{\circ}$ and at lower spindle speeds, 800 and $1200 \mathrm{rpm}$, the serrated chip formation increased linearly. However, at $136^{\circ}$ and $154^{\circ}$ point angles, the serrated formation in the removed chip decreased as shown in Figure 8(c), definitely.

While the requested ductile form was obtained, long and continuous chip morphology with increasing point angle, at $0.025 \mathrm{~mm} / \mathrm{rev}$ feed rate conditions in machining operation, also the tool wear decreased. In addition, with increasing the drill point angle, the chip slenderness ratio decreased.

Continuous, long, and ductile chip morphology with decreasing chip slenderness ratios was obtained with the selected drill point angles $136^{\circ}$ and $154^{\circ}$. As shown in Figure 8(b), decrease in chip slenderness ratio, at $0.050 \mathrm{~mm} / \mathrm{rev}$ feed rate, was only obtained at the drill point angle $154^{\circ}$. But the continuous, long, and ductile chip morphology was also obtained with other drill point angles. In Figure 8(c), while chip slenderness ratio increased under $0.075 \mathrm{~mm} / \mathrm{rev}$ feed rate and $800 \mathrm{rpm}$ spindle speed conditions, the value of this ratio decreased because of increasing the spindle speed.

Here, positive effects were observed when the feed rate and the spindle speed collaterally changed with each other. Also at $0.075 \mathrm{~mm} / \mathrm{rev}$ feed rate, the lowest chip slenderness ratios were obtained with selective drill point angles $136^{\circ}$ and $154^{\circ}$. Moreover, chips were obtained in the requested morphology, and tool wear decreased at these angles. Burning marks on the cutting edge of the tool and chips were seen because of high process temperature during the drilling operations.

4.6. The Effect of the Calculated Chip Slenderness Ratio on Tool Wear. Tool wear is an important identifier for the tool life in machining operations. Less tool wear provides longer tool life. The effect of the drill point angle, spindle speed, and feed rate on the tool wear is shown in Figure 9 in predrilled drilling operations.

At $0.025 \mathrm{~mm} / \mathrm{rev}$ feed rate, with increasing drill point angle, calculated chip slenderness ratio decreased linearly. Moreover, the tool wear quantity decreased as shown in Figure 9(a).

At $0.050 \mathrm{~mm} / \mathrm{rev}$ feed rate, the tool wear increased at higher spindle speeds, as 1200 and $1600 \mathrm{rpm}$, but at lower drill point angles, it decreased as $100^{\circ}$ and $118^{\circ}$. However, at $500 \mathrm{rpm}$ spindle speed and $100^{\circ}$ drill point angle, the tool wear decreased. At $136^{\circ}$ and $154^{\circ}$ point angles, the tool wear decreased for all selected spindle speeds. However, at higher spindle speeds, due to the higher process temperature, there were burning marks on the drill cutting edges as shown in Figure 9(c).

With increasing the feed rate to $0.075 \mathrm{~mm} / \mathrm{rev}$, the tool wear increased only at lower spindle speed and $100^{\circ}$ point angle; with increasing the point angle, the wear quantity of the tool cutting edge increased at $1600 \mathrm{rpm}$ spindle speed.

\section{Conclusions}

In predrilled drilling operations of AISI 1050 steel alloy, HSS drills were employed, and the effect of the selected parameters on the chip slenderness ratio and also the effect of the chip slenderness ratio on the thrust force, the surface roughness, the drilled hole delamination, the tool wear, and the chip morphology were investigated. The derived results in this study were listed below.

The major parameters influential on the chip slenderness ratio were the feed rate and the drill point angle, but the effect of the spindle speed was too small to be negligible; with decreasing the chip slenderness ratio, the thrust force and tool wear decreased, and also the removed chip morphology changed from shorter, brittle, and serrated to continuous, ductile, and free of serrated form. Besides, with increasing the calculated chip slenderness ratio, the surface roughness increased collaterally. However, the chip slenderness ratio did not have any important effect to be taken into consideration on the hole delamination.

Furthermore, with changing point angles from $100^{\circ}$ to $154^{\circ}$, the chip slenderness ratio decreased from 84 to 7 , the 


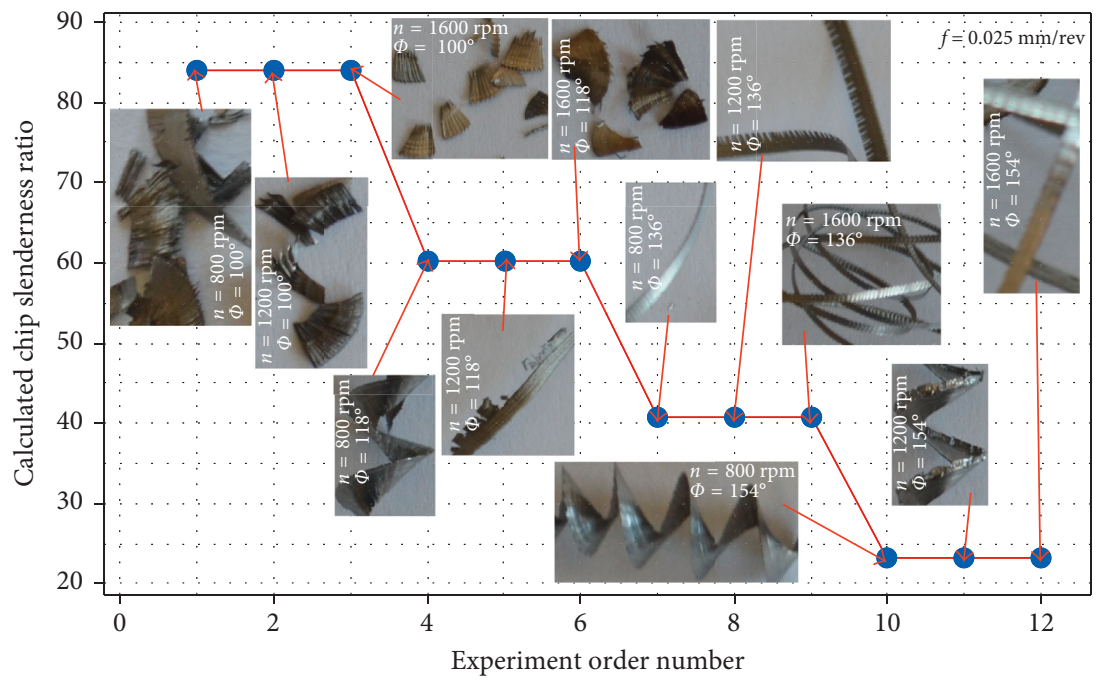

(a)

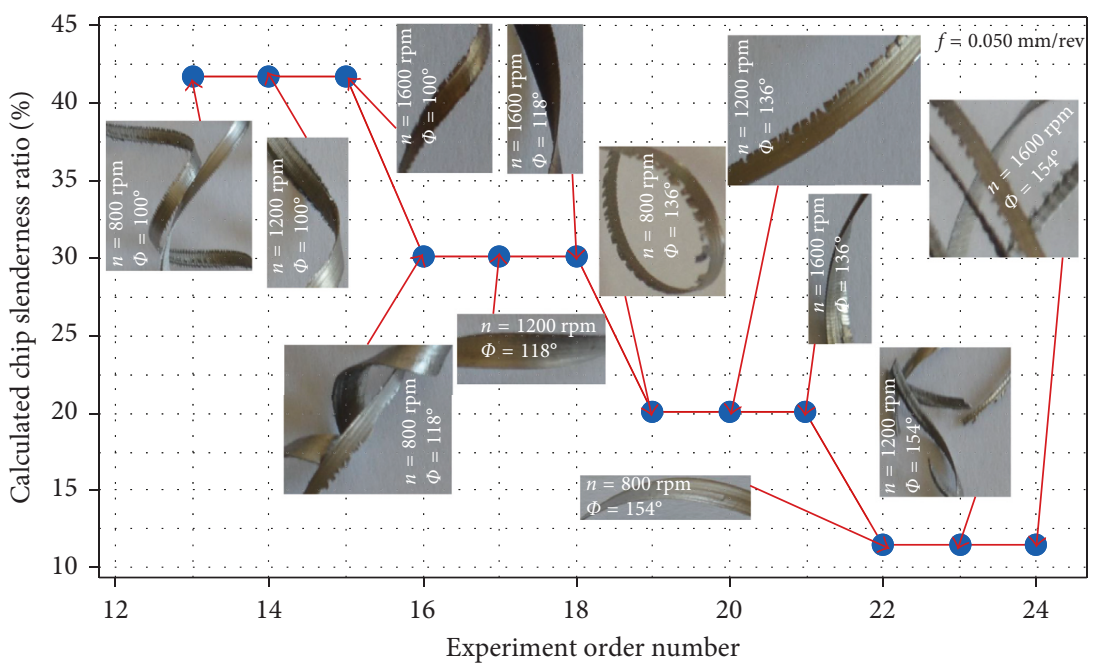

(b)

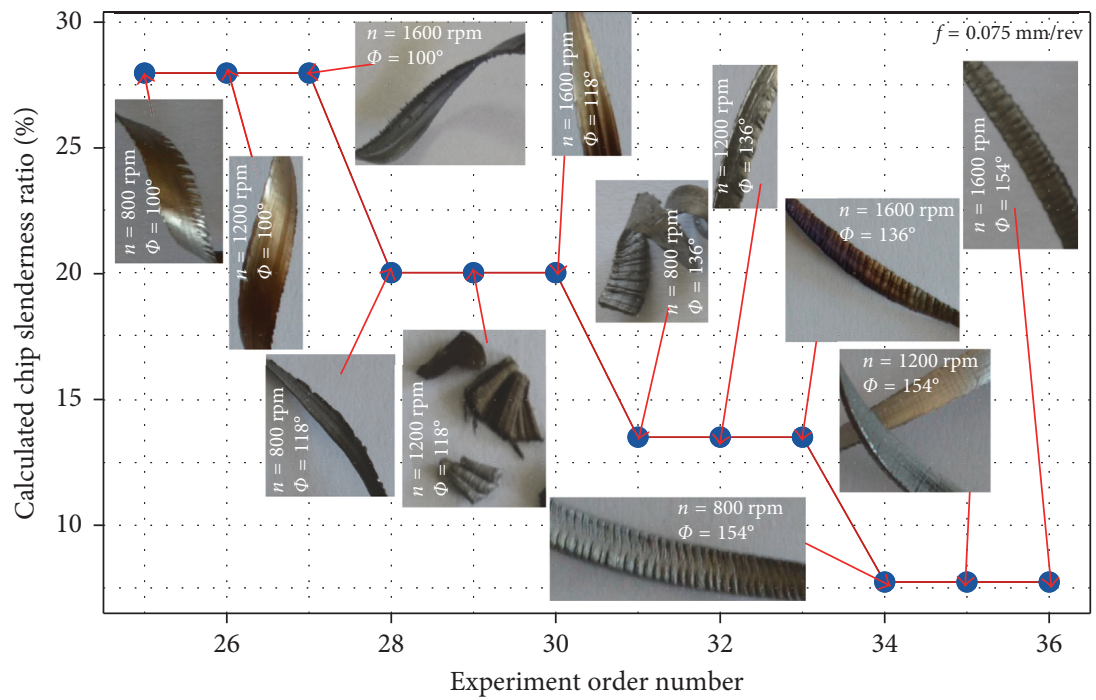

(c)

FIGURE 8: Effects of experimental and theoretical chip slenderness ratios on the chip morphology. (a) $0.025 \mathrm{~mm} / \mathrm{rev}$, (b) $0.050 \mathrm{~mm} / \mathrm{rev}$, and (c) $0.075 \mathrm{~mm} / \mathrm{rev}$ feed rates. 


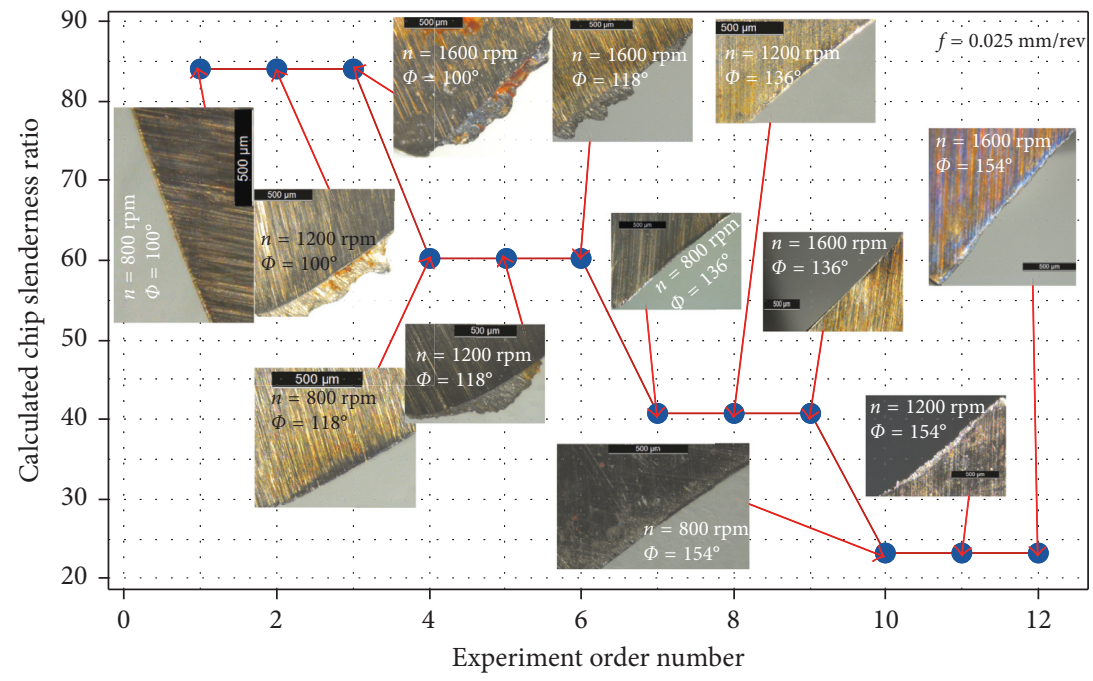

(a)

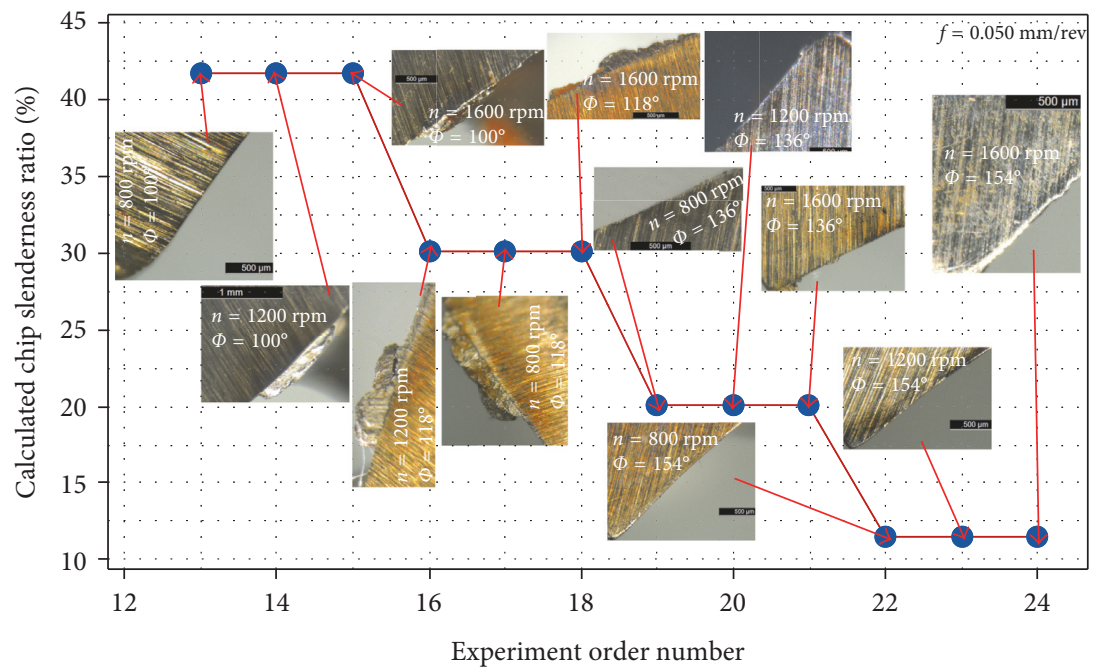

(b)

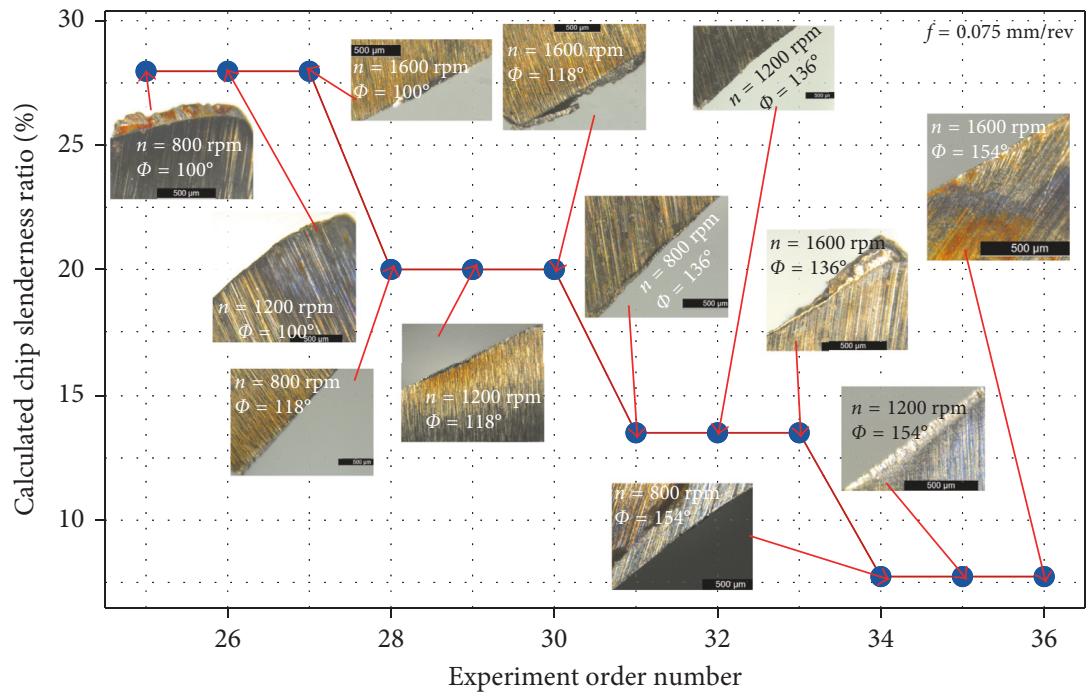

(c)

Figure 9: Effects of experimental and theoretical chip slenderness ratios on the tool wear. (a) $0.025 \mathrm{~mm} / \mathrm{rev}$, (b) $0.050 \mathrm{~mm} / \mathrm{rev}$, and (c) $0.075 \mathrm{~mm} / \mathrm{rev}$ feed rates. 
quantity of the tool wear decreased, and the removed chip morphology was changed from brittle, shorter, and serrated forms, undesired chip forms, to continuous, longer ductile, and free of serrated form, the most desired chip form in machining operations.

\section{Data Availability}

The data used to support the findings of this study are included within the article.

\section{Conflicts of Interest}

The authors declare that they have no conflicts of interest.

\section{References}

[1] A. A. Thakre and S. Soni, "Modeling of burr size in drilling of aluminum silicon carbide composites using response surface methodology," Engineering Science and Technology an International Journal, vol. 19, no. 3, pp. 1199-1205, 2016.

[2] W. C. Chen and C. C. Tsao, "Cutting performance of different coated twist drills," Journal of Materials Processing Technology, vol. 88, no. 1-3, pp. 203-207, 1999.

[3] M. B. Lazar and P. Xiraouchhakis, "Mechanical load distribution along the main cutting edges in drilling," Journal of Materials Processing Technology, vol. 213, no. 2, pp. 245-260, 2013.

[4] S. Kalidas, R. E. Devor, and S. G. Kapoor, "Experimental investigation of the effect of drilling coatings on hole quality under dry and wet drilling conditions," Surface and Coatings Technology, vol. 148, no. 2-3, pp. 117-128, 2001.

[5] G. S. Samy and K. S. Thirumalai, "Measurement and analysis of temperature, thrust force and surface roughness in drilling of AA (6351)- $\mathrm{B}_{4} \mathrm{C}$ composite," Measurement, vol. 103, pp. 1-9, 2017.

[6] N. Z. Karimi, H. Heidary, and G. Minak, "Critical thrust and feed prediction models in drilling of composite laminates," Composite Structures, vol. 148, pp. 19-26, 2016.

[7] Z. Jia, R. Fu, B. Niu, B. Qian, Y. Bai, and F. Wang, "Novel drill structure for damage reduction in drilling CFRP composites," International Journal of Machine Tools and Manufacture, vol. 110, pp. 55-65, 2016.

[8] K. Kalaiselvan, N. Murugan, and S. Parameswaran, "Production and characterization of AA6061- $\mathrm{B}_{4} \mathrm{C}$ stir cast composite," Materials and Design, vol. 32, no. 7, pp. 4004-4009, 2011.

[9] U. Çaydaş, A. Hasçalık, Ö. Buytoz, and A. Meyveci, "Performance evaluation of different twist drills in dry drilling of AISI 304 Austenitic stainless steel," Materials and Manufacturing Processes, vol. 26, no. 8, pp. 951-960, 2011.

[10] K. Palanikumar and A. Muniaraj, "Experimental investigation and analysis of thrust force in drilling cast hybrid metal matrix (Al-15\%SiC-4\%graphite) composites," Measurement, vol. 53, pp. 240-250, 2014.

[11] Y. H. Çelik, H. Yildiz, and C. Özek, "Effect of cutting parameters on workpiece and tool properties during drilling of Ti-6Al-4V," Materials Testing, vol. 58, no. 6, pp. 519-525, 2016.

[12] B. Ramesh, A. Elayaperumal, and S. Satishkumar, "Effect of the standard and special geometry design of a drill body on quality characteristics and multiple performance optimization in drilling of thick laminated composites," Procedia Manufacturing, vol. 97, pp. 390-401, 2014.
[13] P. Feng, J. Wang, J. Zhang, and J. Zheng, "Drilling induced tearing defects in rotary ultrasonic machining of $\mathrm{C} / \mathrm{SiC}$ composites," Ceramics International, vol. 43, no. 1, pp. 791-799, 2017.

[14] J. Wang, P. Feng, J. Zheng, and J. Zhang, "Improving hole exit quality in rotary ultrasonic machining of ceramic matrix composites using a compound step-taper drill," Ceramics International, vol. 42, no. 12, pp. 13387-13394, 2016.

[15] M. Ramulu, P. N. Rao, and H. Kao, "Drilling of $\left(\mathrm{Al}_{2} \mathrm{O}_{3}\right) \mathrm{p} / 6061$ metal matrix composites," Journal of Materials Processing Technology, vol. 124, no. 1-2, pp. 244-254, 2002.

[16] J. P. Davim, "Study of drilling metal-matrix composites based on the Taguchi techniques," Journal of Materials Processing Technology, vol. 132, no. 1-3, pp. 250-254, 2003.

[17] S. Basavarajappa, G. Chandramohan, J. P. Davim et al., "Drilling of hybrid aluminium matrix composites," International Journal of Advanced Manufacturing Technology, vol. 35, no. 11-12, pp. 1244-1250, 2008.

[18] J. P. Davim and A. M. Baptista, "Cutting force, tool wear and surface finish in drilling metal matrix composites," Proceedings of the Institution Mechanical Engineers, Part: E Journal of Process Mechanical Engineering, vol. 215, no. 2, pp. 177-183, 2001.

[19] Y. Altunpak, M. Ay, and S. Aslan, "Drilling of a hybrid Al/SiC/ Gr metal matrix composites," International Journal of Advanced Manufacturing Technology, vol. 60, no. 5-8, pp. 513517, 2012.

[20] A. Taşkesen and K. Kütükde, "Experimental investigation and multi-objective analysis on drilling of boron carbide reinforced metal matrix composites using grey relational analysis," Measurement, vol. 47, pp. 321-330, 2013.

[21] S. Ema, "Effect of twist drill point geometry on torque and thrust," Science Report of the Faculty of Education, Gifu University, vol. 36, pp. 165-174, 2012.

[22] R. Ghosh, R. Sarkar, S. Paul, and S. K. Pal, "Biocompatibility and drilling performance of beta tricalcium phosphate: yttrium phosphate bioceramic composite," Ceramics International, vol. 42, no. 7, pp. 8263-8273, 2016.

[23] U. Çaydaş and M. Çelik, "AA 7075-T6 investigation effects of cutting parameters on surface roughness, tool temperature and feed force," Polytechnic Magazine, vol. 20, no. 2, pp. 419-425, 2017.

[24] Y. H. Çelik, "Investigating the effects of cutting parameters on the hole quality in drilling the Ti-6Al-4V alloy," Materials and Technology, vol. 48, no. 5, pp. 653-659, 2014.

[25] A. Z. Sultan, S. Sharif, and D. Kurniawan, "Chip formation when drilling AISI 316L stainless steel using carbide twist drill," Procedia Manufacturing, vol. 2, pp. 224-229, 2015.

[26] P. A. Rey, J. Ledref, J. Senatore, and Y. Landon, "Modelling of cutting forces in orbital drilling of titanium alloy Ti-6Al-4V," International Journal of Machine Tools \& Manufacture, vol. 106, pp. 75-88, 2016.

[27] R. S. Anand and K. Patra, "Mechanistic cutting force modelling for micro-drilling of CFRP composite laminates," CIRP Journal of Manufacturing Science and Technology, vol. 16, pp. 55-63, 2017.

[28] E. M. Trent, Mechanics of Drilling, Metal Cutting, Metal Cutting Operations and Terminology, University of Birmingham, Birmingham, UK, 1984.

[29] V. P. Astakhov, Drilling System, Drills, Science and Technology of Advanced Operations, Taylor \& Francis Group LLC, Boca Raton, FL, USA, 2014.

[30] M. Kronenberg, The Extended Cutting Speed Law, Machining Science and Application, Theory and Practice for Operation and Development of Machining Processes, Pergamon Press Inc., Oxford, UK, 1966. 


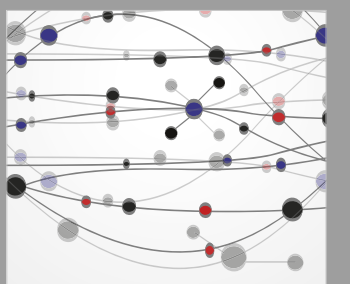

The Scientific World Journal
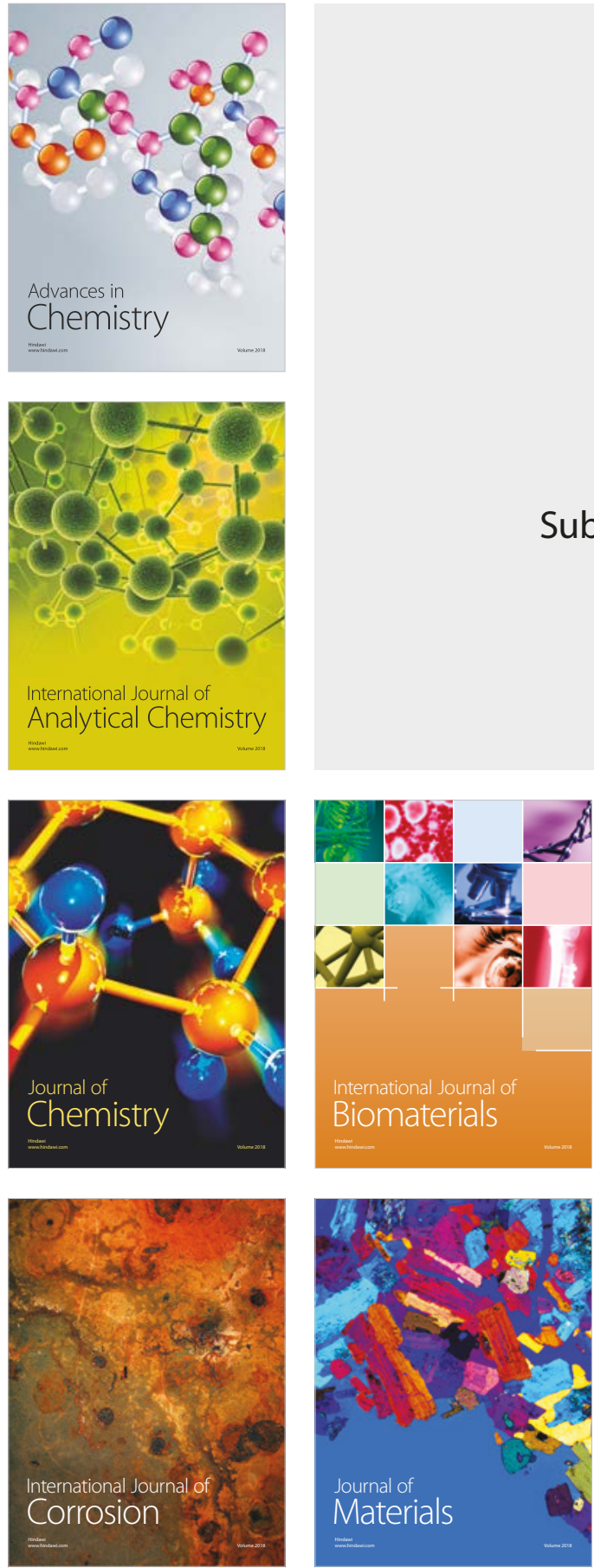

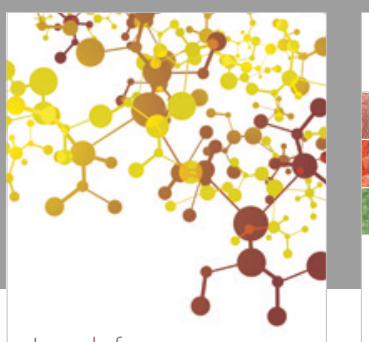

Journal of

Applied Chemistry
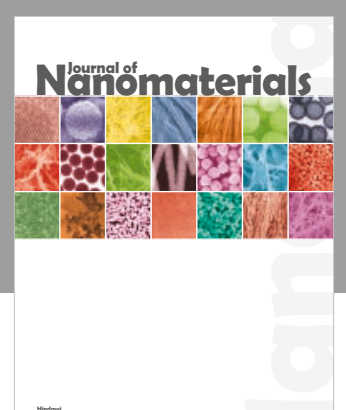

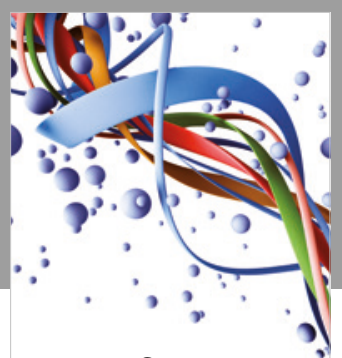

Scientifica

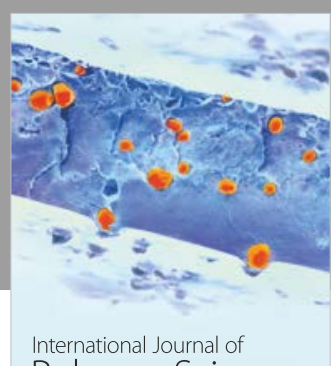

Polymer Science

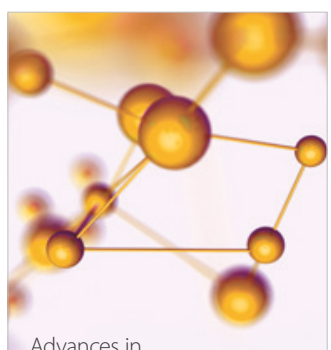

Physical Chemistry
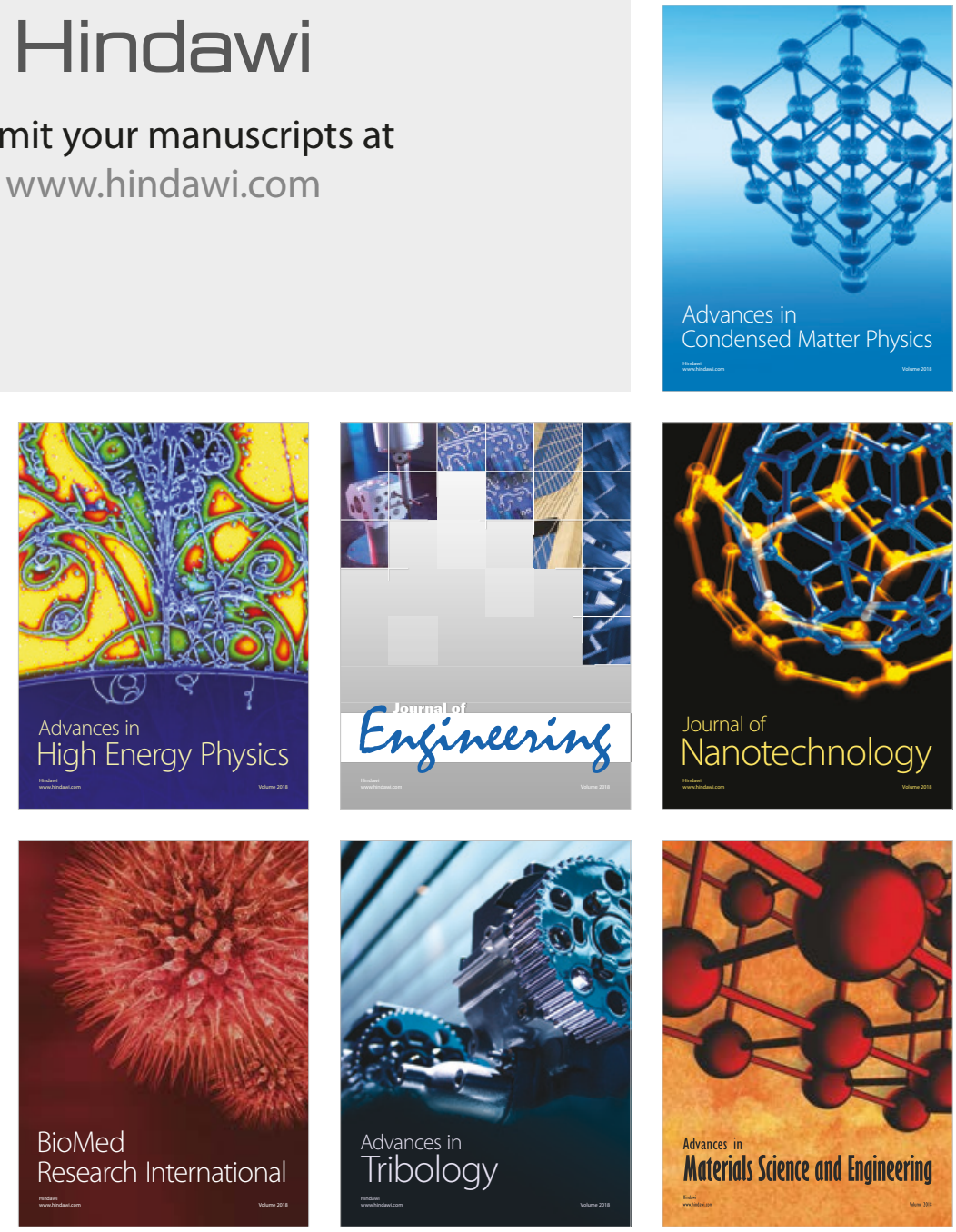